\title{
Toxicology: the blind spot
}

\author{
Sagar S Bhat ${ }^{*}$, Srinivasa Gopala Rao ${ }^{2}$ \\ ${ }^{1}$ First Year MDS, Department of Orthodontics and Dentofacial Orthopaedics, S D M College of Dental Sciences, \\ Dharwad, Karnataka, India \\ ${ }^{2}$ Clinician, Experimental Pathologist and Toxicologist, Retired Professor Emirates and Head, Department of \\ Pathology, The Oxford Dental College, Bengaluru, Karnataka, India
}

Received:10-09-2018 / Revised: 25-09--2018 / Accepted: 07-10-2018

\begin{abstract}
Brief Background: On the $30^{\text {th }}$ anniversary of Bhopal Gas Tragedy, we did a search to find out whether there is a subject called Dental Toxicology that is taught in Dental colleges. The result was there was no college in India which taught toxicology as subject or associated with Oral Medicine. The Bhopal gas tragedy is one of the worst chemical disasters where Methyl Isocyanide (MIC) had lethal short term consequences and serious long term toxicity, genetic instability, probable carcinogenicity, high degree of reproductive effects and teratogenicity. Any tragedy of this magnitude should have made any country sit up and take a vow to prevent any future such incidence in the industry.Discussion: In the field of dentistry normally many potential toxic chemicals are used often on the patients in prosthesis and tooth restoration. These include substances such as Amalgam, triclosan (proven carcinogen), methyl methacrylate, MERCURY, fluoride, polychlorinated biphenyls, BPA ,epoxy resins, composites, implants, artificial crowns etc., which may be toxic to human health, which may cause genetic mutations and even carcinogenic Both FDI (Federation Dentaire Internationale) and IAOMT (International Association of Oral Medicine and Toxicology) in 2013 positively support dentistry free of mercury to begin with, by either reducing mercury in a phased manner or totally Mercury Free Dentistry. Summary and Conclusion: The key areas are: Including the subject of TOXICOLOGY and mechanisms of toxicity not only in medical education but also in dentistry and anything connected to health sciences as a separate subject. This did not happen even after 30 years. With this paper we would like to highlight the potential toxic chemicals, alternative to such chemicals, Identification and how to avoid such toxicity in dentistry.Did Bhopal Tragedy wake us up as a country or is India in deep SLUMBER??
\end{abstract}

Keywords: Toxicology; Toxicity; IAOMT; Dental Curriculum, Medical education, toxic chemicals.

\section{Introduction}

As per Hindu Mythology during "Samudra Manthana", a tug of war between the angels and demons, After churning the eternal ocean, a very concentrated form of poison known as "Aalahala" was produced. And after churning further a life-giving potion called "Amrutha" was obtained. This probably suggests that anything in the most concentrated form and of high potency is a poison and diluting it brings out a property of the drug, which is beneficial.

\section{*Correspondence}

\section{Sagar S Bhat}

First Year MDS, Department of Orthodontics and Dentofacial Orthopaedics, S D M College of Dental Sciences, Dharwad, Karnataka, India E Mail: sagarbhat1994@yahoo.in
(AmitheAmruthamVisham)- Exceed the dose, even the life-giving potion turns poisonous - runs a Sanskrit proverb (An ancient saying over thousands of years becomes a proverb).Ancient Indian contribution to the science of medicine appears to be that, at high doses most of the substances exhibit poisonous characteristics and the corollary that, take a poison and dilute it, the drug characteristics emerge.

"What is there that is not poison? All things are poison and nothing (is) without poison. Solely the dose determines that a thing is not a poison." -Paracelsus (1493-1541) - Father of Toxicology according to Western Science.

It was one of the deadliest midnights in the history of India on $2^{\text {nd }} / 3^{\text {rd }}$ December 1984 , when the disaster that took place, shook the whole world at once. Thousands and thousands of people were killed by the chemical that was leaked out from the Union Carbide Factory at 
Bhopal, India. At that time the Indian population was somewhere around 800-900 million people, but not even a SINGLE citizen in India could recognize what was that chemical that caused this deadliest chemical disaster by killing thousands and thousands of people. Any tragedy of this magnitude should have made any country sit up and take a vow to prevent any future such incidents in industry. Bhopal gas tragedy is one of the worst chemical disasters where Methyl Isocyanide (MIC) had lethal short-term consequences and serious long-term toxicity, genetic instability, probable carcinogenicity, high degree of reproductive effects and teratogenicity.

What is TOXICOLOGY?

The subject that deals with the unwanted effects of any substance (drugs, chemicals, xenobiotics) is Toxicology. Toxicology is the study of the poisonous effects of substances. So, every substance is a poison until proven otherwise. For example: Curarie(muscle relaxants - extracted from South American Arrow Poison), Tetarodotoxin(extracted from toad skin), Nicotine, Salicylic Acid (Adathoda plant) etc, before the drugs therapeutic effect, their poisonous effects were known in almost all of them. (Figure 1 and 3) Quadrants of Toxicology (Figure 2):

There are four quadrant effects of toxins : All the substances can be classified as based on effects into four quadrants:

$\checkmark$ Observable and Controllable.

$\checkmark$ Observable and Non Controllable.

$\checkmark \quad$ Non Observable and Controllable.

$\checkmark \quad$ Non Observable and Non Controllable.

These toxins have three types of effects like Systemic and Target Organ toxicity (short term toxicity and long term toxicity), Genotoxicity (Mutagenicity and Carcinogenicity) and Teratogenicity (which affects the fetus).

Importance of Nutrition on General and Dental Health and Toxins (Figure 4)
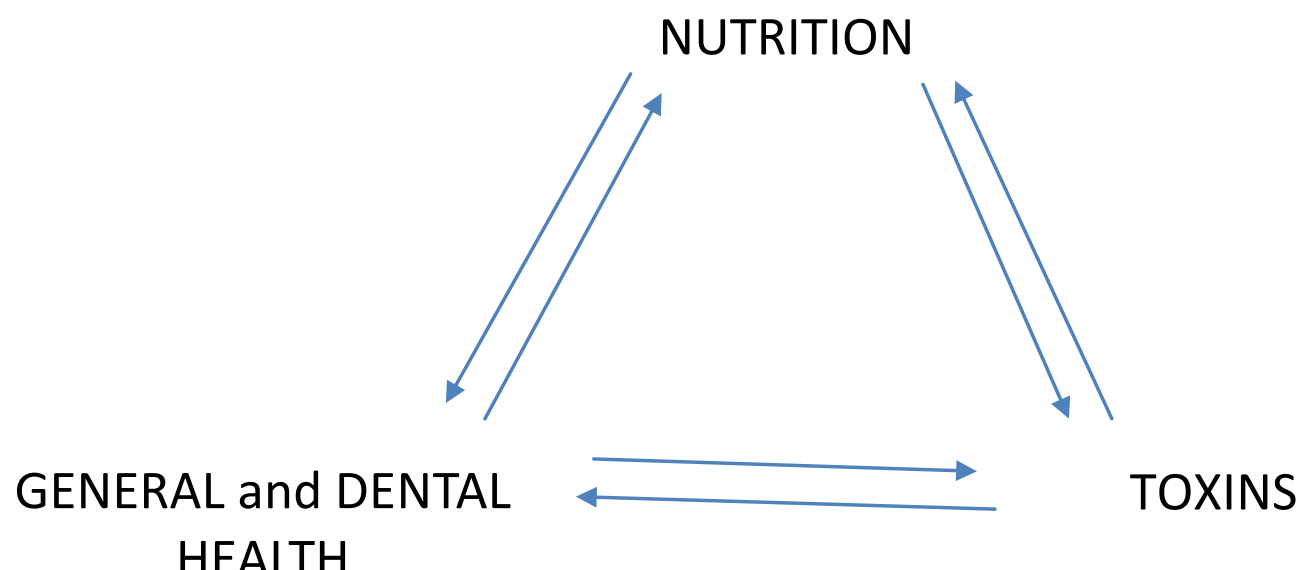

CENTRAL THEME

Fig 4:Triangular relationship between Nutrition, General Health, Dental Health and Toxins

Which is not stressed by most of the dental clinicians!! Nutrition and toxicity go hand in hand[8,9]Probably food is the major medium through which the toxins enter the body[24]Toxins can enter through the food, alter the metabolism and be the cause of lifestyle disorders and this third factor explains sudden increase in the incidence of these disorders[10,24]

Obesity risks: Obesity risk may be due to 3 major factors[11,12]

- Genes: Lifestyle, Diet, Genetic Legacy, Natural variation and random mutation (Genetic Drift) in genes controlling hypothalamic energy balance set points (DRIFTY GENE HYPOTHESIS) [12,13]

- Epigenetics: Heritable changes and modifications in DNA that don't alter DNA sequence eg.DNA methylation and covalent modification of histone tails, is involved in basic cell functions including proliferation, differentiation and growth[13,14] DNA methylation patterns are affected by environmental influences like in-utero environment, exposure to xenobiotics and stresses 
which are responsible for susceptibility to obesity[14,15]

- Fetal Environment: Increased susceptibility to obesity can be programmed in-utero, early and post natal life. FETAL ORIGIN OF ADULT DISEASE HYPOTHESIS - Studies in women and experimental models clearly indicate the maternal diet and body composition during pregnancy influence aspects of metabolism and appetite regulation in offsprings[16,17]

Disciplines of Toxicology:

Discipline 1:--Drug Toxicity: the organism as a system. It is also called as Target organtoxicology. It shows the mechanism and sights where toxicities can be produced[26] (Figure 5)

Discipline 2:--environmentaltoxicity: a global system. It $\mathrm{s}$ also called as predictivetoxicology. Technologies developed at different levels of presence of toxins in the environment, in the contact, in the body fluids and then biomarkers which they produce. Predictive Toxicology. Eg: Dioxin in the environment [27,31]. (Figure 6)

Toxicity Related to excess caloric intake/obesity:

Adaptive and physiological response to positive energy balance produced as a result of overeating and inadequate physical activity result in toxicity over long term[18]Short term coordinated changes in metabolic pathways in white adipose tissue in response to overfeeding results in excess energy storage in form of triglycerides and increase the size of pre-existing adipocytes(hypertrophy), and this also leads to formation of new adipocytes through hyperplasia[17,18]Plasma concentration of NonEsterified Fatty Acids (NEFA) leads to increased ingestion of high fat diets leading to hydrolysis of triglycerides in fat and accumulation of triglycerides in non-adipose tissues like liver, skeletal muscle and pancreas as lipid droplets[16,17] So excess of NEFA and lipid metabolites leads to direct and indirect toxic actions leading to insulin resistance, inflammation and tissue damage[26]. So adipose tissue from obese individuals release chemokines and cytokines called as ADIPOKINES, which contributes to metabolic inflammation[4,5] The NEFA and other factors released from adipose tissue contribute to the metabolic syndrome "Met S" in obese people[26-28]Metabolic Syndrome is a cluster of lifestyle disorders. This includes increased serum insulin and cancer risk associated with obesity, insulin resistance, disruption in lipid homeostasis (Dyslipidemia), elevated Blood Pressure, increased risk of development of Cardiovascular Disorder, Non Alcoholic Fatty Liver Disease (NAFLD), Reproductive dysfunction, increased overall mortality and decrease lifespan with increased calorie intake, body weight and adiposity[6,7]But Calorie Restriction (CR) has substantially shown to increase Lifespan[29.30]

Role of Toxicology in dentistry:In dentistry, there are many potential toxic chemicals, used often on the patients in preparing prosthesis and tooth restoration. These include substances such as Amalgam, triclosan, methyl methacrylate, MERCURY, fluoride, polychlorinated biphenyls, BPA ,epoxy resins, composites, implants, artificial crowns etc., which may be toxic to human health, which may cause genetic mutations and even carcinogenic[34,31] Both FDI (Federation Dentaire Internationale) and IAOMT (International Association of Oral Medicine and Toxicology) 2013 positively support dentistry free of mercury to begin with, by either reducing mercury in a phased manner or totally mercury free dentistry[1,2,31]International Association of Oral Medicine and Toxicology (IAOMT):In 1984, thirteen dentists were discussing a seminar they had just attended on the dangers of mercury from dental amalgam fillings. So, like thirteen musketeers vowing "all for one and one for all," they set out to find the evidence, or failing that, to sponsor new research that would provide the answers they sought. The fundamental Mission of the association was: to promote the health of the public at large. Essentially, the Academy shall continually examine and compile scientific research relating to the biocompatibility or oral/dental materials. This agenda also ensured a more informed use of these materials in clinical practice. Within these confines, the Academy helped to Accumulate and disseminate scientific information, Promote relevant

Promote funding for research and education, Promote education of the public, professional organizations, and other groups, by providing scientific information, promote non-invasive scientifically sound therapies, provide advisory services if/when required.

Role in education: shows the public that they are up to speed in the basics of biocompatible dentistry, and methods for safely dealing with mercury exposure from amalgam.

Role in public Education in specific: They support the effort to inform consumers about health risks from amalgam mercury and water fluoridation, and support efforts toward eliminating these risks. They have testified before regulatory agencies about the environmental effects of dental mercury in wastewater, and support regulations to separate mercury from the waste stream of dental offices. 


\section{Discussion}

Dioxin (1,3,7,9-TetraChloroDibenzoDioxin: TCDD) : It acts Receptor as AhR, shared with the pollutants, xenobiotics and endogenous compounds, It helps in Induction of XMEs (CYP1A1) which helps with adaptation and stress response and lastly helps in Regulation of dozens of othergeneS[31]

Seveso Dioxin Disaster, Italy( AParadoxical Classical Disaster): On July 10, 1976, an explosion at a northern Italian chemical plant released a thick, white cloud of dioxin that quickly settled on the town of Seveso, north of Milan. Its effects on people was: nausea, blurred vision and, especially among children, the disfiguring sores of a skin disease known as chloracne. Early health investigations including liver function, immune function, neurologic impairment, and reproductive effects yielded inconclusive results. Chloracne was the only effect established with certainty. Dioxin Contamination during Dioxin Disasater at Times Beach, Missouri, Mississippi ( Double Disaster)[31].Current studies suggests that apart from widespread toxicity due to mercury among dental patients and workers, there are other environmental toxins like 7,12Dimethylbenz[a]anthracene (DMBA), Tributyltin (TBT),Biphenyl A(BPA), anticancer chemotherapy(CT) and Total Body Irradiation (TBI) which can cause abnormalities in dental development in the fetus and probably other organs as well. The evidence comes from:Study done by EijaSamela suggests that maternal smoking during pregnancy can reduce child's tooth size. One main component of tobacco smoke is 7,12 Dimethylbenz[a]anthracene(DMBA) and organic tin compound Tributyltin(TBT) has shown to impair bone formation and mineralization in experimental animals but its effect on tooth has not been studied earlier. Exposure to organic toxicants, well established cause for enamel hypomineralization is excess fluoride intake[32] Exposure to DMBA, TBT significantly reduced the size of tooth germs, impaired deposition and mineralization of enamel and dentin. TBT exposure has moderately enhanced apoptotic cell death mainly in epithelial tissues in first molar, in tooth germs it reduces Osteocalcin (Ocn) gene expression in odontoblast but increase its presence in epithelial compartment of tooth and it reduces matrix metalloproteinase 20 (Mmp-20) expression in both ameloblast and odontoblast[17,32]TBT can be transferred to infants through breast feeding. During the use of fluoride toothpaste by child, these compounds may react with fluoride leading to interference with dental hard tissue formation. This work provides experimental evidence that developmental toxicity of fluoride and digoxin is potentiative and it also showed that structurally and mechanistically different chemicals impair tooth development at relatively low concentration[32]

PaivaiHoltta $^{33}$ studied the effect of high dose anticancer chemotherapy(CT), Total Body Irradiation(TBI), \& age at Stem cell transplant Recipient(SCT) in relation to tooth agenesis, microdontia and root crowns(R/C) ratios of permanent teeth in $56 \mathrm{SCT}$. Conclusion is in SCT, the effect of high dose anticancer CT \& TBI on developing tooth were marked. All the patients were affected. High dose anticancer $\mathrm{Ct}$ caused severe damage. TBI caused aberration in teeth of all SCT's.

Trouble in India at different levels

- At Government Level: The trouble in India is the Policy makers or the Government as such, are not giving importance that is required regarding toxicity, toxic effects caused by any drug or chemical that is used on the patients as such during the treatment and its overall effect on the environment.

- At Institutional Level: This is because both medical and dental colleges do not have Department of Toxicology, and even if they have they don't emphasize the importance of having a knowledge about each chemical that is used in each procedure of the treatment.

- At Student Level: Toxicology as a subject was not taught in any medical or dental colleges or ordinary colleges then in 1984 nor is it being taught now.

Implications: In dentistry as in other health fields sometimes we use substances knowingly or unknowingly which results in harming the patients. Sometimes the unborn child or the dental practitioners who handle harmful substances as exemplified by Mercury in amalgams are also affected. The effort to have "Mercury free dentistry" is a step-in preventing toxicity. There are other substances as we have mentioned and still others to come in the wake of a new subject the so called NANO Particles/Nanotechnology, which can not only cause nanotoxicity but also nanopollution and the dental community should be alert to the potential dangers of any substance. So introduction of a subject like toxicology will spread awareness and prevent tragedies like Thalidomide,Minamata disease, Bhopal gas disaster etc. 


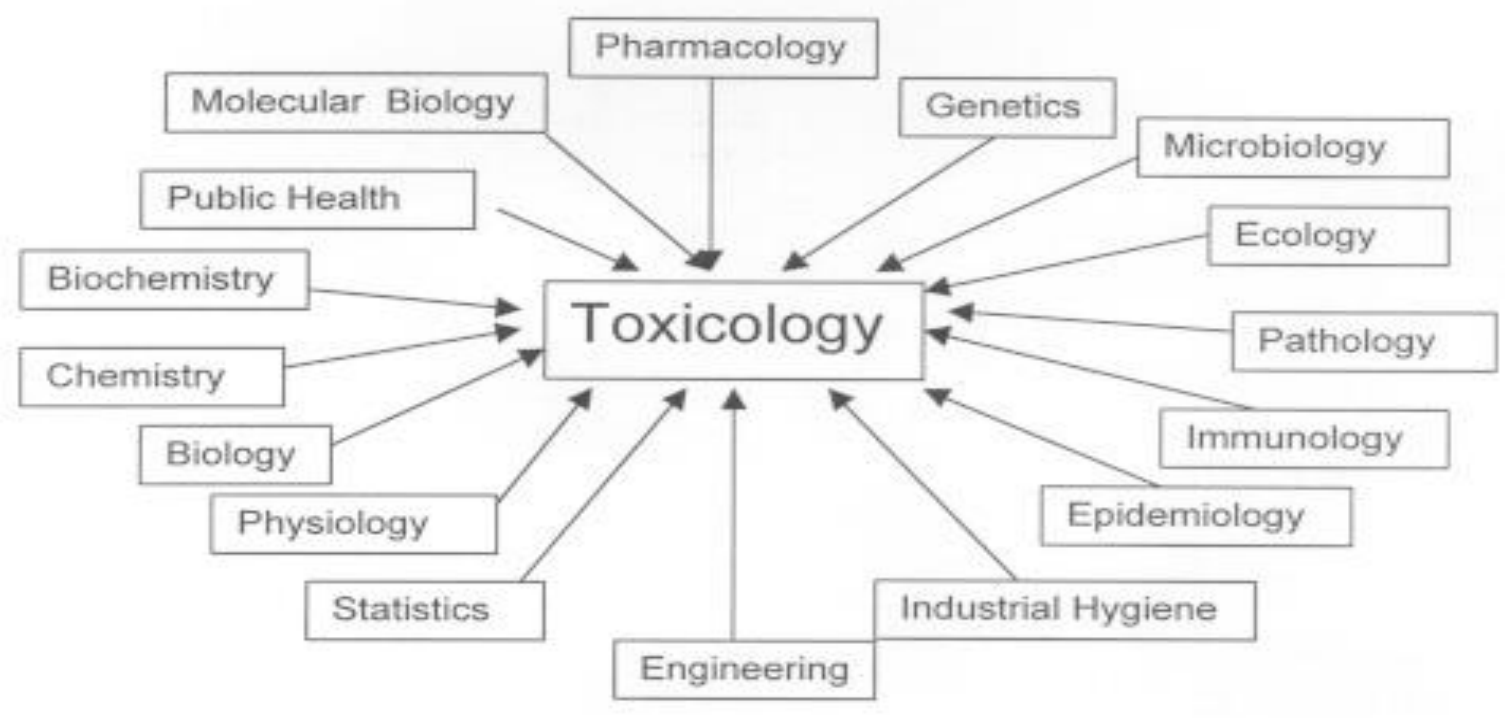

Fig 1: Since all the subjects have directly or indirectly derived their strength from Toxicology or toxins. This could even be termed as a - THE MOTHER OF ALL BIOLOGICAL SCIENCES. (Courtesy: Casarett and Doull's Toxicology: The Basic Science of Poisons, $8^{\text {th }}$ edition,Curtis D. Klaassen).

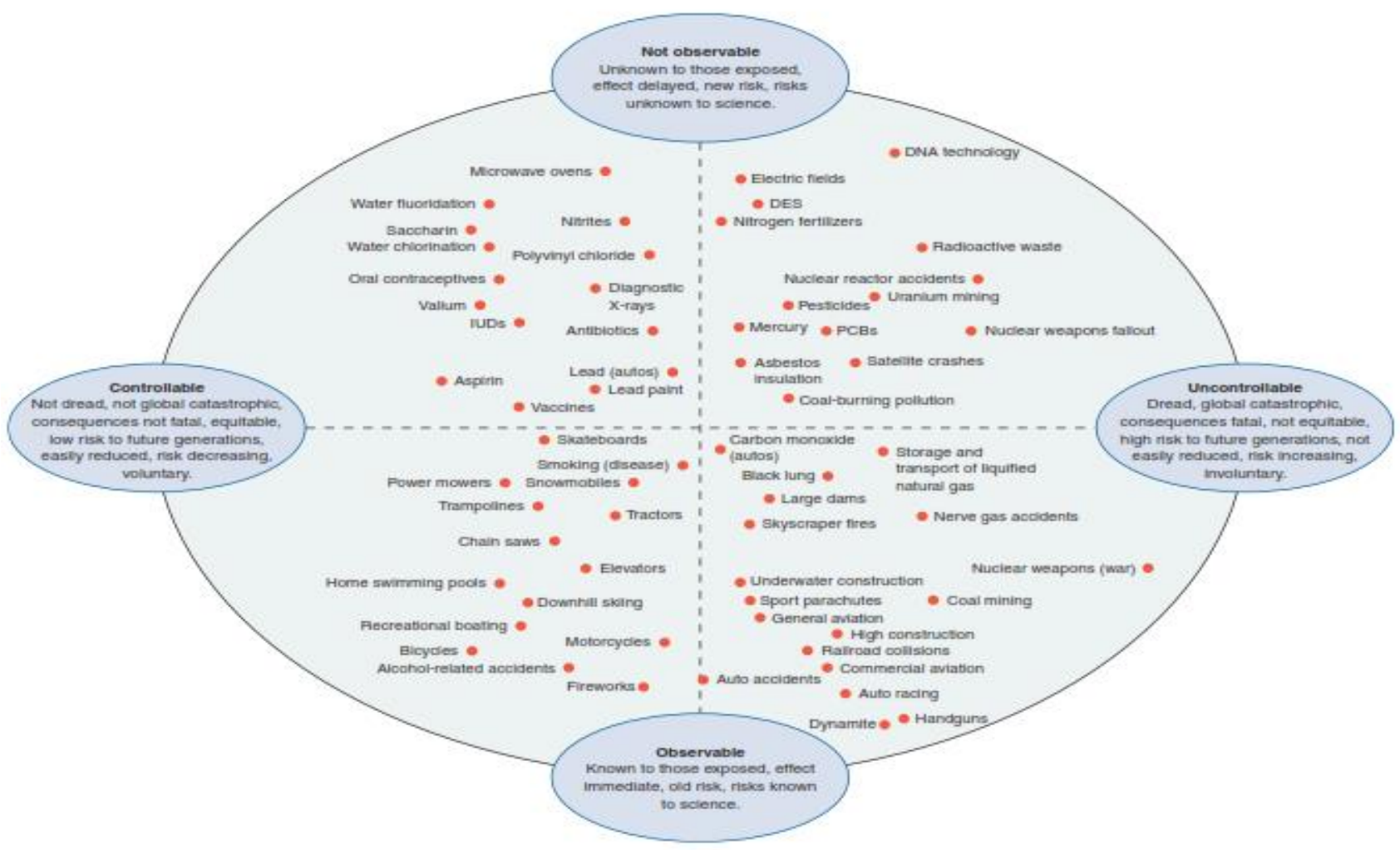

Fig 2: The world of toxicology which is represented in the form of Four Quadrants. (Courtesy: Casarett and Doull's Toxicology: The Basic Science of Poisons, $8^{\text {th }}$ edition, Curtis D. Klaassen). 


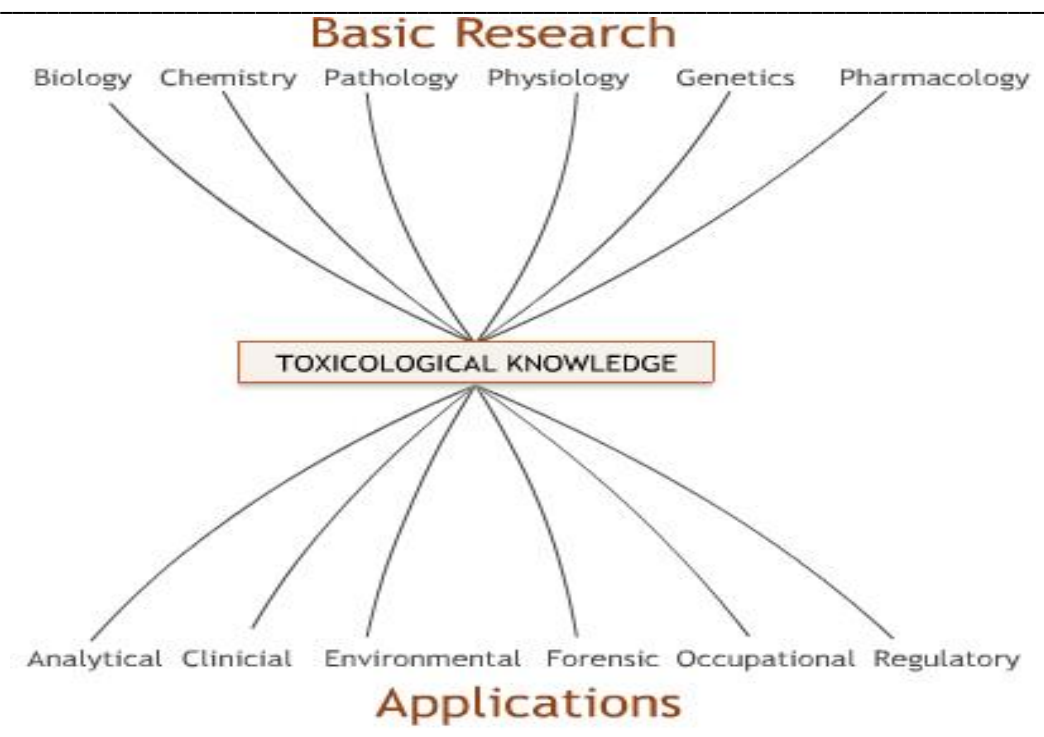

Fig 3: Contribution of toxicology to those science - Toxicology encompasses different field - mother of biological sciences. (Courtesy: Casarett and Doull's Toxicology: The Basic Science of Poisons, $8^{\text {th }}$ edition, Curtis D. Klaassen).

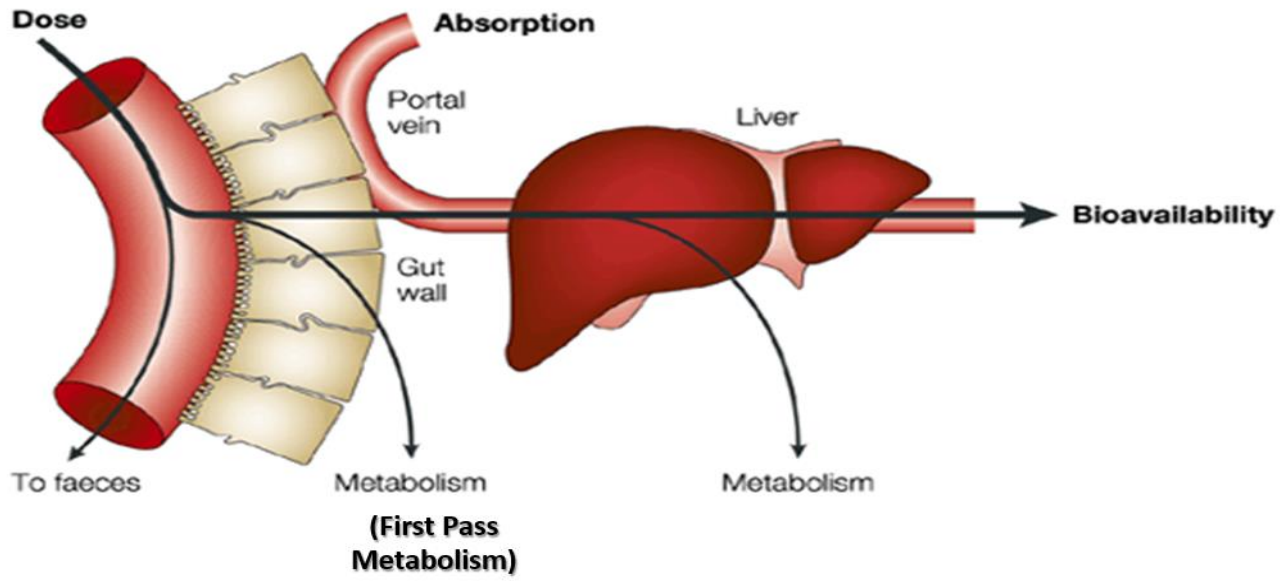

Fig 5: Drug Toxicity. (Courtesy: Casarett and Doull's Toxicology: The Basic Science of Poisons, $8^{\text {th }}$ edition, Curtis D. Klaassen) 


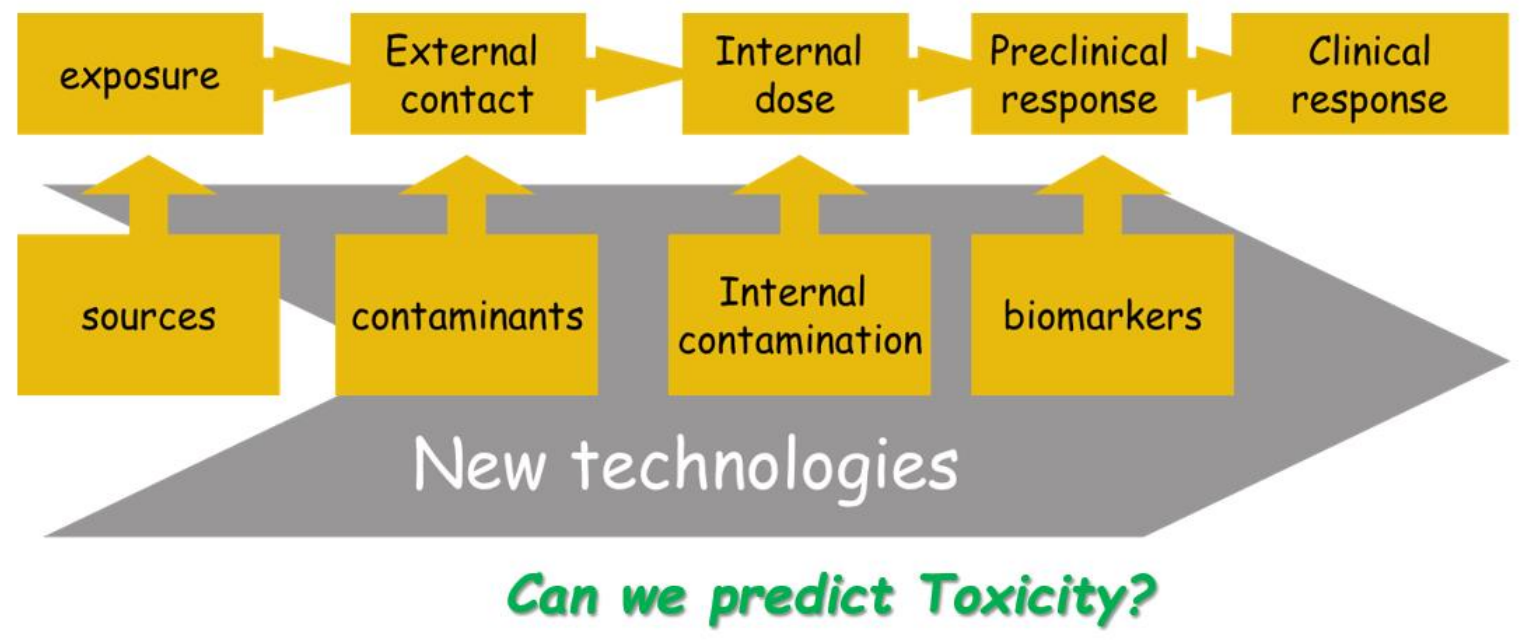

Fig 6: Environmental Toxicity. (Courtesy: Casarett and Doull's Toxicology: The Basic Science of Poisons, $8^{\text {th }}$ edition, Curtis D. Klaassen)

\section{Conclusion}

Any substance introduced in to the body or environment has the potential to cause toxicity. The Real Danger exists in knowing and not acknowledging the danger and doing nothing about it.

From inability to let alone;

From too much zeal for the new and contempt for what is old;

From putting knowledge before wisdom, and

Science before art and cleverness before common sense; from treating

patients as cases; and from making the cure of the disease more

grievous than the endurance of the same, Good Lord, deliver us.

- Sir Robert Hutchison

Did Bhopal Tragedy wake us up as a country or is India in deep SLUMBER????

\section{References}

1. Albrektsson $\mathrm{T}$ et al, Is marginal bone loss around oral implants the result of a provoked foreign body reaction?,Clin Implant Dent Relat Res. 2014;16(2):155-65.

2. Qian $\mathrm{J}$ et al, Reasons for marginal bone loss around oral implants, Clin Implant Dent Relat Res. 2012;14(6):792-807.

3. AthinaBakopoulou et al, Molecular Toxicology of Substances Released from Resin-Based Dental Restorative Materials, Int. J. Mol. Sci. 2009;10: 3861-3899
4. Cancer, inflammation and the AT1 and AT2 receptors, Journal of Inflammation 2004, 1:3

5. Bosma-den Boer et al, Chronic inflammatory diseases are stimulated by current lifestyle: how diet, stress levels and medication prevent our body from recovering, Nutrition \& Metabolism 2012; 9:32.

6. Stankov S V, Definition of Inflammation, Causes of Inflammation and Possible Anti-inflammatory Strategies, The Open Inflammation Journal, 2012; 5:1-9.

7. Inflammation: Gearing the journey to cancer, J.K. Kundu, Y.-J. Surh / Mutation Research 2008;6:1530

8. Carocho M, Ferreira IC, A review on antioxidants, prooxidants and related controversy: natural and synthetic compounds, screening and analysis methodologies and future perspectives, Curr Med Chem. 2010;17(28):3262-88

9. Wojcik $\mathrm{M}^{1}$, Burzynska-Pedziwiatr I, Wozniak LA, A review of natural and synthetic antioxidants important for health and longevity,\# 2000 Society of Chemical Industry. J Sci Food Agric 0022 $\pm 5142 / 2000 / \$ 30.001744$

10. Cora J Dillard and J Bruce German, Phytochemicals: nutraceuticals and human health

11. aga_fnc_2006_clinical_consequences_of_under_a nd_over_nutrition.pdf

12. Sugars, energy metabolism, and body weight control,Am J ClinNutr2003;78(suppl):850S-7S

13. Carbohydrate intake and obesity, $\mathrm{Eu} J$ ClinNutr.2007;61 (Suppl 1):S75-S99. 
14. Roberts $\mathrm{K} \mathrm{V}$, Carbohydrate Intake and Obesity: An Association that Needs "Refining", J AmDent Association, 2009;1(2):21

15. Verzar F, fat metabolism, Annu. Rev. Biochem. 1938;7:163-188

16. Noland $C \mathrm{R}$ et al, Carnitine Insufficiency Caused by Aging and Overnutrition Compromises Mitochondrial Performance and Metabolic Control J. Biol. Chem. 2009 ;284: 22840-22852.

17. Rugg-Gunn AJ, Al-Mohammadi SM, Butler TJ., Malnutrition and developmental defects of enamel in 2- to 6-year-old Saudi boys,1998;32(3):181-92.

18. Tulchinsky H T, Micronutrient Deficiency Conditions:Global Health Issues,Public Health Reviews, 32(1):243-255.

19. Dietary Reference Intakes for Calcium, Phosphorous, Magnesium, Vitamin D, and Fluoride.Institute of Medicine, Washington, DC: National Academy Press; 1997.

20. Altura BM, Altura BT. Magnesium: Forgotten Mineral in Cardiovascular Biology and Therogenesis. In: International Magnesium Symposium.

21. Dean C. The Magnesium Miracle, New Perspectives in Magnesium Research. London: Springer-Verlag; 2007:239-260, New York: Ballantine Books; 2007.

22. Seelig M, Rosanoff A. The Magnesium Factor. New York: Avery; 2003.

23. Ovesen L, Chu R, Howard L. The influence of dietary fat on jejunostomy output in patients with severe short bowel syndrome. Am J ClinNutr1983;38(2):270-277.

24. Nutrition versus toxicology of manganese in humans: evaluation of potential biomarkers, Neurotoxicology. 1999;20(2-3):205-12.
25. Finley JW, Davis CD, Manganese deficiency and toxicity: are high or low dietary amounts of manganese cause for concern?,Biotoxicity Journal, 1999;10(1):15-24.

26. Moynihan J P, The role of diet and nutrition in the etiology and prevention of oral diseases, Bulletin of the World Health Organization 2005;83:694699

27. Lucas M R, Assocation or causation: evaluating the links between the environment and disease, Bulletin of the World Health Organization 2005;83(10):793-795

28. Hideo Orimo et al, Nutrition education in Japanese medical schools:a follow-up survey, Asia Pac J ClinNutr 2013;22 (1):144-149

29. Aparnasheetal et al, Malnutrition and its Oral Outcome - A Review, JCDR, 2012:23

30. Anderson H G, Effect of Glycemic Carbohydrates on Short-term Satiety and Food Intake,2003: (II)S17-S26.

31. AnuKiukkonen, Toxicity of dioxin to developing teeth and salivary glands, An experimental study, Department of Pediatric and Preventive Dentistry and Department of Oral Pathology Institute of Dentistry, University of Helsinki, Finland, 2006, Ph.D thesis.

32. EijaSalmela, The effects of organic environmental toxicants on hard tissue formation in developing tooth, An in vitro study in mice, Institute of Dentistry, Department of Pediatric and Preventive Dentistry, Faculty of Medicine, University of Helsinki, 2011, Ph.D thesis.

33. PäiviHölttä, aberrations of permanent teeth after high-dose anticancer therapy in childhood, A Study on Stem Cell Transplant Recipients, Helsinki 2005, Ph.D Thesis

Conflict of Interest: None

Source of Support: Nil 